\title{
Crystal structure and solid state ionic conductivity of molecular crystal composed of lithiumbis(trifluoromethanesulfonyl)amide and 1,2-dimethoxybenzene in a 1:1 molar ratio
}

\author{
Makoto Moriya, ${ }^{\mathrm{a}, \mathrm{b}, \mathrm{c}, *}$, Daiki Kato, ${ }^{\mathrm{c}}$ Yoshiko Hayakawa, ${ }^{\mathrm{c}}$ Wataru Sakamoto, ${ }^{\mathrm{c}}$ Toshinobu Yogo ${ }^{\mathrm{c}}$ \\ ${ }^{a}$ Department of Chemistry, Graduate school of Science, Shizuoka university, 836 Ohya, Suruga-ku, \\ Shizuoka 422-8529, Japan \\ ${ }^{b}$ JST PRESTO, 4-1-6, Honcho, Kawaguchi, Saitama 332-0012, Japan \\ ${ }^{c}$ EcoTopia Science Institute, Nagoya University, Furo-cho, Chikusa-ku, Nagoya 464-8603, Japan \\ *Corresponding author, +81-54-238-4753, e-mail address: moriya.makoto@shizuoka.ac.jp (Makoto \\ Moriya)
}

\begin{abstract}


heating LiTFSA with DMB in 1:1 molar ratio. Single crystal X-ray diffraction study of 1 revealed that thecompound possesses a dinuclear structure with five-coordinate lithium centers bridged by TFSA anions. AC impedance measurements showed that ionic conductionthrough the crystallites of 1 takes place via a hopping mechanism at ambient temperature.
\end{abstract}

\section{Introduction}

Recently, molecular crystals (MCs) exhibiting solid-state lithium ion conductivity via a hopping mechanism have been reported. [1-11]These MCs, consisting of lithium salts with small molecules or polymers, show ordered arrays of component units, which correspond to ionic conduction paths in the crystal lattice. Interestingly, the conductive properties of MCs are greatly affected by their structural features, which are easily modified by altering the component molecules or counter anions. [4-7],[10],[11] Therefore, elucidation of the structure-conductivity relationships of MCs isimportantto the development of novel solid electrolyte materials.

We have previously reported the synthesis of ion conductive $\mathrm{MCs}$ using $\mathrm{Li}\left\{\mathrm{N}\left(\mathrm{SO}_{2} \mathrm{CF}_{3}\right)_{2}\right\}$ (LiTFSA) and small molecules containing ether groups as starting materials.[9,10]Since TFSA anion shows not only high dissociativity but also multiple coordination ability, LiTFSAis a suitable starting material to obtain ion conductive MCs. These LiTFSA-based MCs exhibit selective lithium ion diffusivity since sulfonyl groups of TFSA anions behave as component units of conduction pathsas

(C) 2015. This manuscript version is made available under the Elsevier user license http://www.elsevier.com/open-access/userlicense/1.0/ 
well as the ether molecules andthat inhibit anion diffusion. Recently, we have also foundthat the ion conductive properties of amine-based MCs, $\mathrm{Li}(\mathrm{TFSA})$ (diamine) and $\mathrm{Li}\left(\mathrm{CF}_{3} \mathrm{SO}_{3}\right)$ (diamine), relate to the structural features of their ionic conduction paths. [11]These studies for the ether and diamine-based MCs indicated that the coordination environment of the lithium center influences the activation energy for lithium ion hopping. Furthermore it was found that the intermolecular $\mathrm{Li}-\mathrm{Li}$ distance affects ionic conductivity.

Herein, we investigate the precise structural control of MCs by altering the molar ratio of small molecules to LiTFSA,for understanding the applicability of the above mentioned structure-conductivity relationship. Previously, various kinds of crystal structures for MCs composed of LiTFSA with dimethoxyethane (DME) were reported by altering the molar ratio of LiTFSA/DME. $[12,13]$ This study indicates that controlling the molar ratio between the lithium salt andsmall molecules can be a tool for altering the structure of MCs as well as structural modification of the component molecules. However, the melting points of MCs containingDME are not high enough to evaluate the structure-conductivity relationship. Therefore, we employ 1,2-dimethoxybenzene (DMB) as a component molecules to increase the melting points of MCs. In this work, we synthesized a novel ionic conductive MC, [Li(TFSA)(DMB)] (1), and compared its structure and conductivity to those of previously reported MCs, [Li(TFSA)(DMB) $)_{2}$ (2) [10] and [Li(TFSA) $\left.\left\{\left(\mathrm{H}_{3} \mathrm{C}\right)_{2} \mathrm{NCH}_{2} \mathrm{CH}_{2} \mathrm{~N}\left(\mathrm{CH}_{3}\right)_{2}\right\}\right]$ (3)[11,12] (Fig. 1).

\section{Experimental}

LiTFSA was purchased from Kishida Chemical Co. DMB was purchased from Tokyo Chemical Industry Co.LiTFSA and DMB were dried under reduced pressure for 3 days before use.

Ionic conductivity was measured by using a disc of electrolyte. The disc was sandwiched between two SUS plates in a two-electrode cell and sealed in a closed vessel. The vessel was placed into a bench-top-type chamber (ESPEC, SU-241). Conductivity data were collected by ac impedance measurements using a Biologic VMP3. All cells for the electrochemical experiments were assembled in an argon-filled glovebox (MBraun, UNIlab2000) and equilibrated at the operating temperature for at least $3 \mathrm{~h}$ before performing any measurements.

Differential scanning calorimetry analysis was performed by using an SII EXSTAR DSC6220 instrument operated at a heating rate of $10{ }^{\circ} \mathrm{C} \mathrm{min}^{-1}$ under $\mathrm{N}_{2}$ atmosphere; $\mathrm{Al}_{2} \mathrm{O}_{3}$ was used as a reference material. Elemental analysis was performed on a EuroVector EuroEA3000 elemental analyzer.

$\mathrm{X}$-ray diffraction patterns at different temperature were measured using Rigaku, SmartLabdiffractometer using $\mathrm{Cu} K_{\alpha}$ radiation with a monochromatorand a temperature control system (Anton Paar, TCU 110).

Synthesis of 1: The reaction flask was charged with LiTFSA and DMB under nitrogen 
atmosphere. The reaction mixture was heated at $110{ }^{\circ} \mathrm{C}$ to give a colorless homogeneous solution. The flask was then cooled to room temperature. The crystallization of 1 gradually proceeded over a few months. The obtained colorless crystals were washed with dry pentane and dried under reduced pressure at room temperature for 1 day to yield 1. Anal.Calcd for $\mathrm{C}_{10} \mathrm{H}_{10} \mathrm{~F}_{6} \mathrm{LiNO}_{6} \mathrm{~S}_{2}$ : C, 28.24; $\mathrm{H}$, 2.37; N, 3.29. Found: C, 27.99; H, 2.16; N, 3.47. Melting point: $94.7^{\circ} \mathrm{C}$.

A single crystal was mounted on a loop using oil (CryoLoop, Immersion Oil, Paratone, Hampton Research Corp.). The diffraction data were collected on a Bruker SMART APEX CCD diffractometer with graphite monochromatedMoKa radiation $(\lambda=0.71073 \AA)$ under a cold nitrogen stream. An empirical absorption correction was applied using SADABS. The structure was solved by the direct method and refined by full-matrix least-square on $F^{2}$ using SHELXTL. All non-hydrogen atoms were refined with anisotropic displacement parameters. All hydrogen atoms were located on calculated positions and refined as rigid groups.

Crystal data for 1: $\mathrm{C}_{10} \mathrm{H}_{10} \mathrm{~F}_{6} \mathrm{LiN}_{2} \mathrm{O}_{6} \mathrm{~S}_{2}$; triclinic; $P 2{ }_{1} / \mathrm{c}$ (No. 14); $a=10.773(2) \AA, b=$ 14.661(3) $\AA, c=11.382(3) \AA, \beta=105.223(4){ }^{\circ}, V=1734.8(7) \AA^{3} ; Z=4 ; \mathrm{F}(000)=856 ; \mu=0.395$

$\mathrm{mm}^{-1} ; \rho_{\text {calc }}=1.628 \mathrm{~g} \mathrm{~cm}^{-3} ; 8851$ reflections $\left(2 \theta<50.0^{\circ}\right) ; 3049$ unique $\left(R_{\text {int }}=0.0341\right) ; R_{1}=0.0473$ (I $>2 \sigma(\mathrm{I})), w R_{2}=0.1317$ (all data), $\mathrm{GoF}=1.070 . \mathrm{CCDC}$ reference number 1046318 .

\section{Results and discussion}

MC 1 was synthesized by heating a mixture of DMB and LiTFSA in 1:1 molar ratio at $110{ }^{\circ} \mathrm{C}$ to give a viscous liquid, followed by cooling at room temperature to afford colorless single crystals for several months. The melting point of 1 was estimated to be $94.7^{\circ} \mathrm{C}$ using differential scanning calorimetry (DSC) as shown in Fig. 2. Due to the low content of DMB, MC 1 shows higher melting point than $2\left(57.7^{\circ} \mathrm{C}\right)$, which contain two molar equivalents of DMB toLiTFSA.[10]

The crystal structure of $\mathbf{1}$ determined by X-ray diffraction study is depicted in Fig. 3. MC $\mathbf{1}$ was afforded as a dilithium compound with five-coordination lithium centers in a trigonal bipyramidal structure. Interestingly, the structure of $\mathbf{1}$ was quite similar to that of dilithium MC $\mathbf{3}$ while it was different from that of $\mathbf{2}$, whichis a mononuclear compound with a six-coordination lithium center. [12] TFSA anions in 1 bridged two lithium centers through sulfonyl groups in a chelate and terminal coordination mode like that of $\mathbf{3}$. The average $\mathrm{Li}-\mathrm{O}$ distance of $\mathbf{1}$ was estimated to be $2.03 \AA$, which was shorter than that of 2 (2.11 $\AA)$ and 3 (2.09 $\AA)$. [10,12] Additionally, the average $\mathrm{Li}-\mathrm{N}$ distance of $\mathbf{3}$ was calculated to be $2.10 \AA$, which is similar to the $\mathrm{Li}-\mathrm{O}$ length of $\mathbf{2}$ and 3.[12]From the packingviewin Fig. 4a, ordered arrays of lithium ions in 1corresponding to ionic conduction paths were confirmed. The closest intermolecular $\mathrm{Li}-\mathrm{Li}$ distance of 1 was calculated to be

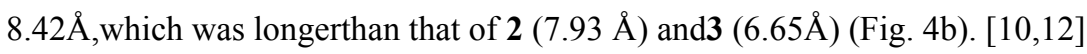

The ionic conductivity of $\mathbf{1}$ measured by ac impedance method is displayed in Fig. 5 with those of $\mathbf{2}$ and $\mathbf{3}$. The Cole-Cole plots of $\mathbf{1}$ showed only one semicircle and a low-frequency spike 
like that of previously reported ionic conductive MCs. [2-7],[10],[11] This indicates relatively small grain boundary resistance compared to the bulk resistance for 1 . The Arrhenius plot of 1 shows linearitysimilar to that of $\mathbf{2}$ and $\mathbf{3}$, which indicates selective lithium ion diffusion via a hopping mechanism. The ionic conductivity of $\mathbf{1}$ was lower than that of $\mathbf{2}$ and $\mathbf{3}$. The activation energy for ion diffusion was calculated to be $78.1 \mathrm{~kJ} \mathrm{~mol}^{-1}$ for $\mathbf{1}$.The order of activation energies for $\mathbf{1}-\mathbf{3}$ is described as $\mathbf{3}\left(39.1 \mathrm{~kJ} \mathrm{~mol}^{-1}\right)<\mathbf{1}\left(78.1 \mathrm{~kJ} \mathrm{~mol}^{-1}\right) \approx \mathbf{2}\left(83.6 \mathrm{~kJ} \mathrm{~mol}^{-1}\right)$. [10,11]Additionally, the pellet of crystal 1 becomes soft above $60{ }^{\circ} \mathrm{C}$ nevertheless this compound has a melting point at $95{ }^{\circ} \mathrm{C}$.Due to the plasticization of $1 \mathrm{in}$ a tight sealed cell, it was difficult to measure the accurate thickness of pellet. For the reason,we showed the ion conductivity of 1 only between 0 and $50{ }^{\circ} \mathrm{C}$. In the XRD pattern of 1 at different temperature, the diffraction peaks slightly broadened and several peaks disappeared under thermal condition (Fig. 6). We suspect that the decrease of crystallinity causes the plasticization of $\mathbf{1}$.

We reported that the closest intermolecular $\mathrm{Li}-\mathrm{Li}$ distance affects the value of ionic conductivity throughout the MCs. $[10,11] \mathrm{We}$ also found that the average $\mathrm{Li}-\mathrm{O}$ and $\mathrm{Li}-\mathrm{N}$ lengths of the MCs play a critical role in the activation energy of ion hopping when the MCs possess same coordination numbers. [10,11]Similar structure-conductivity relationship was observed between $\mathrm{MCs} 1$ and 3 with five-coordination lithium centers. Because of longer intermolecular $\mathrm{Li}-\mathrm{Li}$ distance and the shorteraverage Li-O lengths of $\mathbf{1}$ than those of $\mathbf{3}, \mathrm{MC} \mathbf{1}$ showed low ionic conductivity and the large activation energy compared to those of $\mathbf{3}$, which means lithium ion hopping through $\mathbf{1}$ is inhibited compared to MC 3 .

The ionic conductivityof $\mathbf{1}$ and $\mathbf{2}$ also reflected the structural feature of these compounds. The longer intermolecular $\mathrm{Li}-\mathrm{Li}$ distances of $\mathbf{1}$ than that of $\mathbf{2}$ cause the low ionic conductivity of 1rather than that of 2 .On the other hand, the activation energy of $\mathbf{1}$ and $\mathbf{2}$ of ion hopping was comparable, although the coordination number of $\mathbf{1}$ was different from that of $\mathbf{2}$. This result suggests thatthe disadvantageous lithium ion hopping through $\mathbf{1}$ derived from the short $\mathrm{Li}-\mathrm{O}$ bond length was canceled by the small coordination number of $\mathbf{1}$ (five-coordination) compared to that of $\mathbf{2}$ and $\mathbf{3}$ (six-coordination).These results support that the elongation of bond lengths around the lithium center,the decreaseincoordination number of the lithium ion, and the reduction of the ion hopping length represented as the intermolecular $\mathrm{Li}-\mathrm{Li}$ distances areimportantin obtaining highly conductive MCs.

\section{Conclusion}

In conclusion, we synthesized a novel lithium ion conductive MC $\mathbf{1}$ by altering the molar ratio of DMB from that of previous reported MCs 2. We also investigated the crystal structure and solid-state ionic conductivity of $\mathbf{1}$. A comparison of structural and conductive features of $\mathbf{1}$ with those of $\mathbf{2}$ and $\mathbf{3}$ confirmed the structure-conductivity relationship. The conductivity and ion-hopping 
activation energy of 1-3 are influenced by the intermolecular $\mathrm{Li}-\mathrm{Li}$ distance and the coordination environment of the lithium centers.

\section{Acknowledgement}

We thank Prof. M. Kondo of Shizuoka University for the elemental analysis. This work was supported by JST PRESTO program and The Public Foundation of Chubu Science and Technology Center.

\section{References}

[1] T. Nakamura, T. Akutagawa, K. Honda, A. E. Underhill, A. T. Coomber, R.H. Friend, Nature 394 (1998) 159-162.

[2] G.S. MacGlashan, Y.G. Andreev, P.G. Bruce, Nature 398 (1999) 792-794

[3] Z. Gadjourova, Y.G. Andreev, D.P. Tunstall, P.G. Bruce, Nature 412 (2001) 520-523

[4]Z. Stoeva, I.M. Martin-Litas, E. Staunton, Y.G. Andreev, P.G. Bruce, J. Am. Chem. Soc. 125 (2003)4619-4626.

[5] E. Staunton, Y.G. Andreev, P.G. Bruce, J. Am. Chem. Soc. 127 (2005)12176-12177.

[6] C. Zhang, D. Ainsworth, Y.G. Andreev, P.G. Bruce, J. Am. Chem. Soc. 129 (2007) 8700-8701.

[7] C. Zhang, Y.G. Andreev, P.G. Bruce, Angew. Chem. Int. Ed. 46 (2007) 2848-2850.

[8] M. Matsuo, S, Orimo, Adv. Energy Mater. 1 (2011) 161-172.

[9] M. Moriya, H. Kitaguchi, E. Nishibori, H. Sawa, W. Sakamoto, T. Yogo, Chem. Eur. J. 18 (2012) 15305-15309.

[10] M. Moriya, D. Kato, W. Sakamoto, T. Yogo, Chem. Eur. J. 19 (2013) 13554-13560.

[11] M. Moriyia, K. Nomura, W. Sakamoto, T. Yogo, CrystEngComm 16 (2014) 10512-10518.

[12]M.G. Davidson, P.R. Raithby, A.L. Johnson, P.D. Bolton, Eur. J. Inorg. Chem. (2003) 3445-3452.

[13] D. Brouillete, D. E. Irish, N. J. Taylor, G. Perron, M. Odziemkowski, J. E. Denoyers, Phys. Chem. Chem. Phys. 4 (2002) 6063-6071.

[14]W. A. Henderson, F. McKenna, M. A. Khan, N. R. Brooks, V. G. Young Jr., R. Frech, Chem. Mater. 17 (2005) 2284-2289.

\section{Figure captions}

Fig. 1.Molecular structures of MCs 1-3. 
Fig. 2. DSC curve of MC 1.

Fig. 3. Crystal structure of MC 1 (Li: yellow, C: gray, N: blue, O: red, F: green, S: dark yellow. Thermal ellipsoid is $40 \%$ probability. Hydrogen atoms are omitted for clarity.).

Fig. 4. Packing view of $\mathbf{1}$ along $a$-axis (top) and molecular arrangement of $\mathbf{1}$ (bottom)(Li: yellow, C: gray, N: blue, O: red, F: green, S: dark yellow. Hydrogen atoms are omitted for clarity.).

Fig. 5. Ionic conductivities of 1-3 as a function of temperature (1: red, 2: blue, 3: purple).

Fig. 6. XRD patterns of $\mathbf{1}$ at different temperature. 


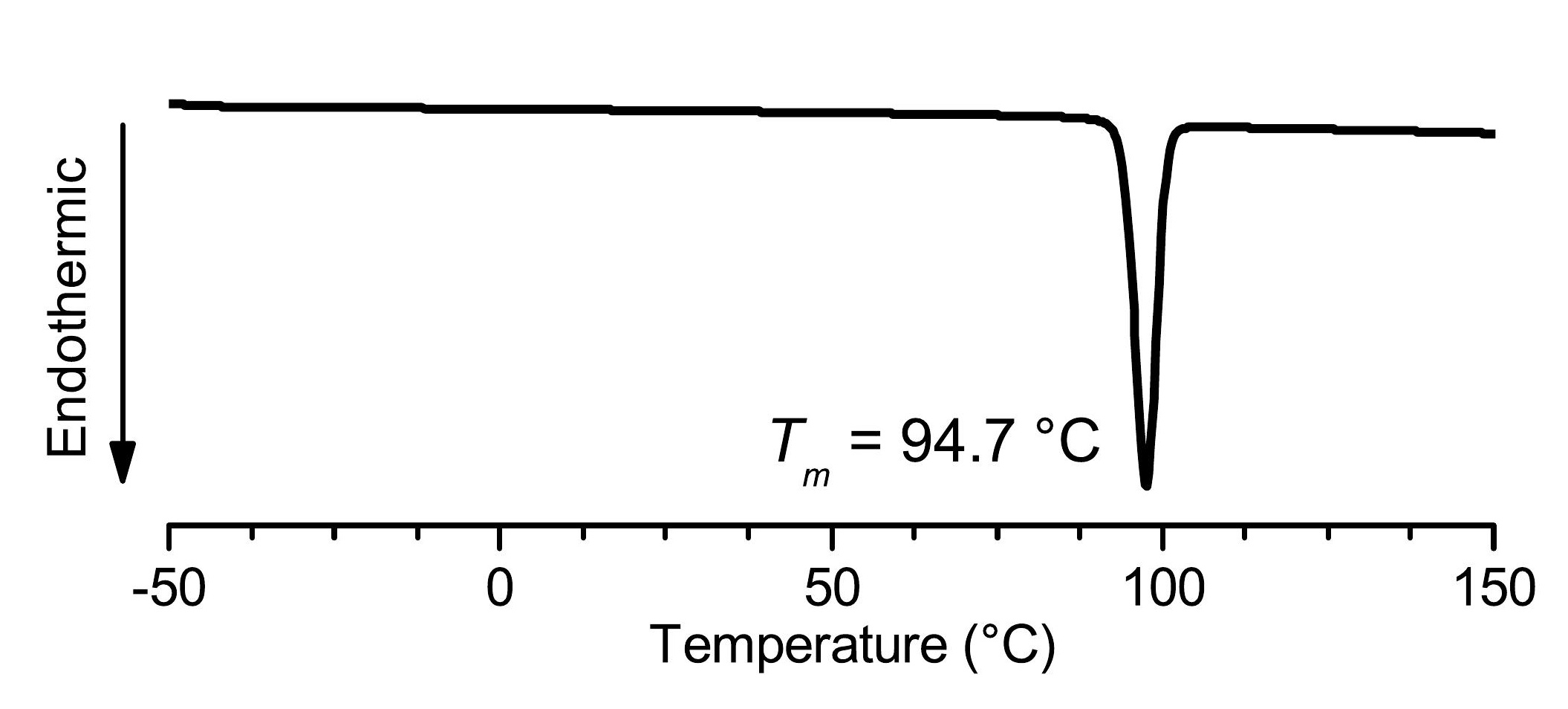

Figure(2)

Figure(2) 



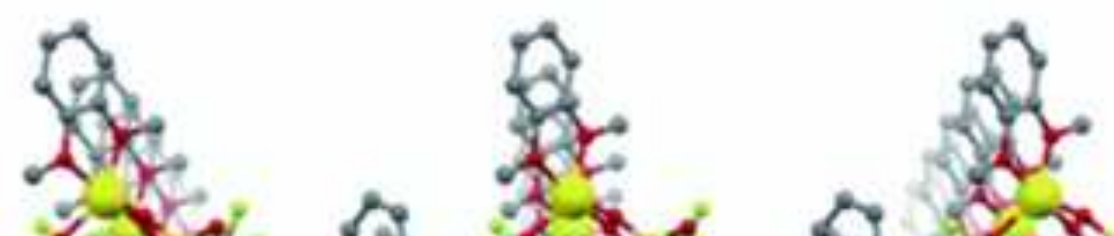

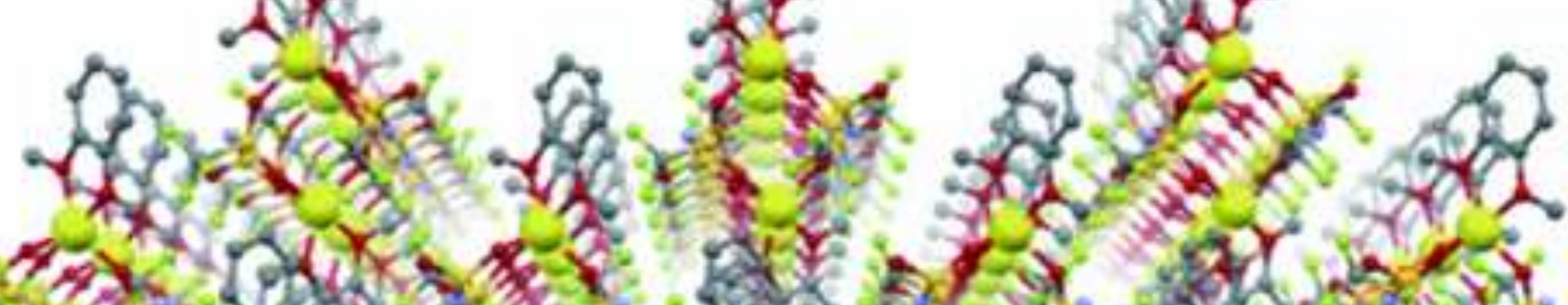

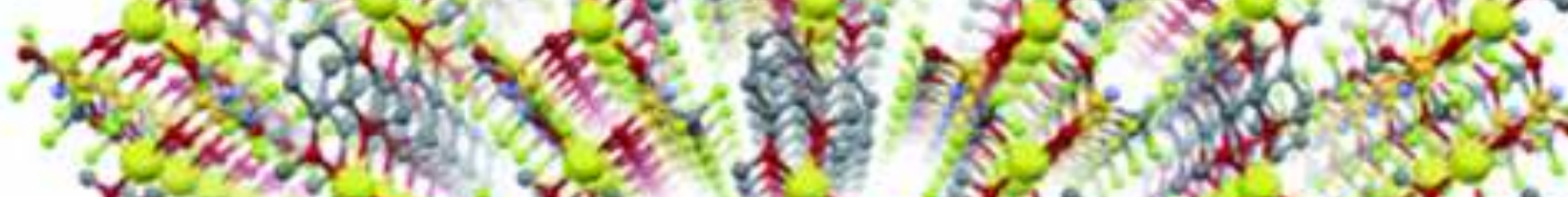

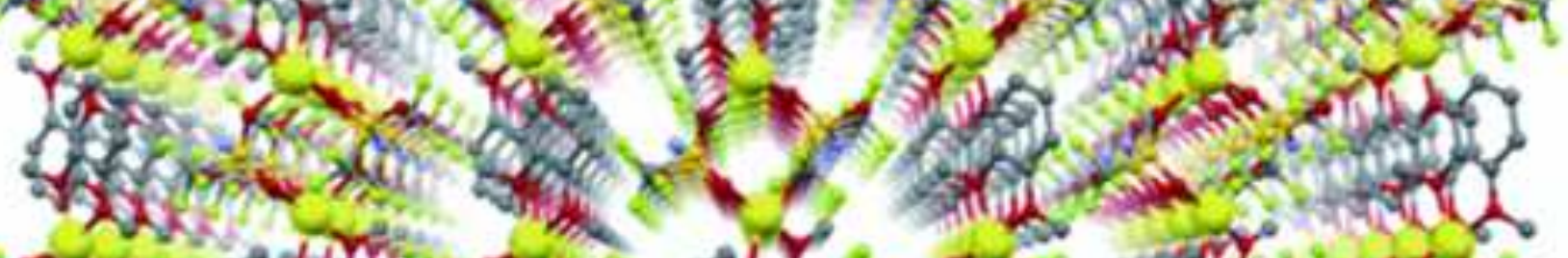
a.?

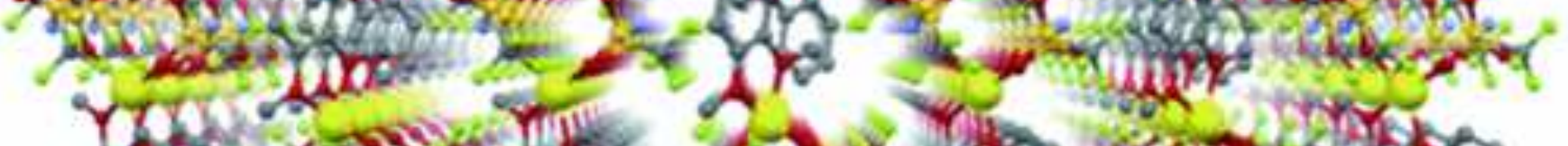

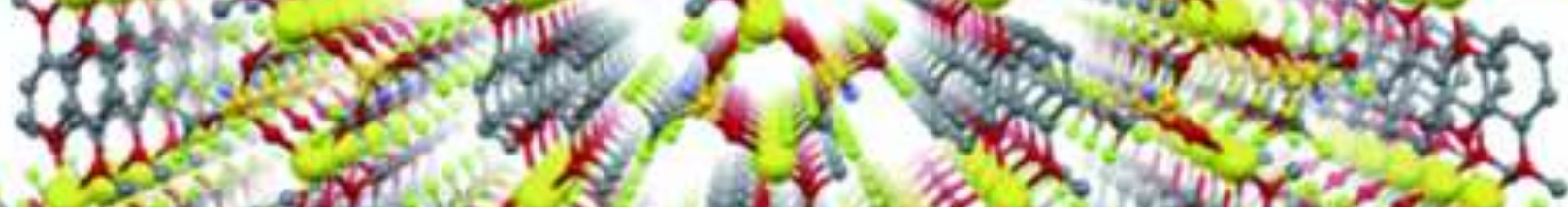

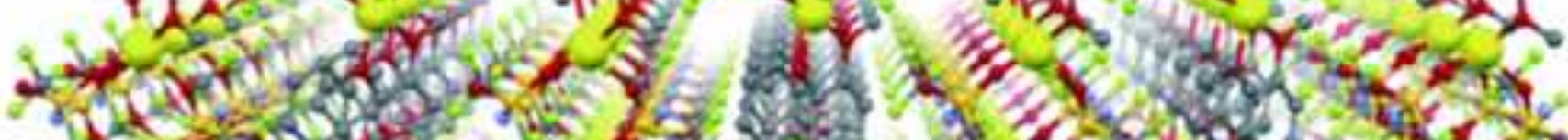
2 a

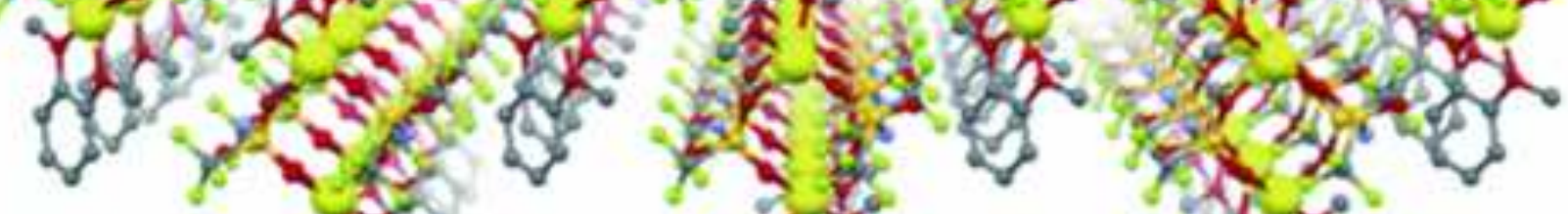
toys: $\frac{28}{28}$ 

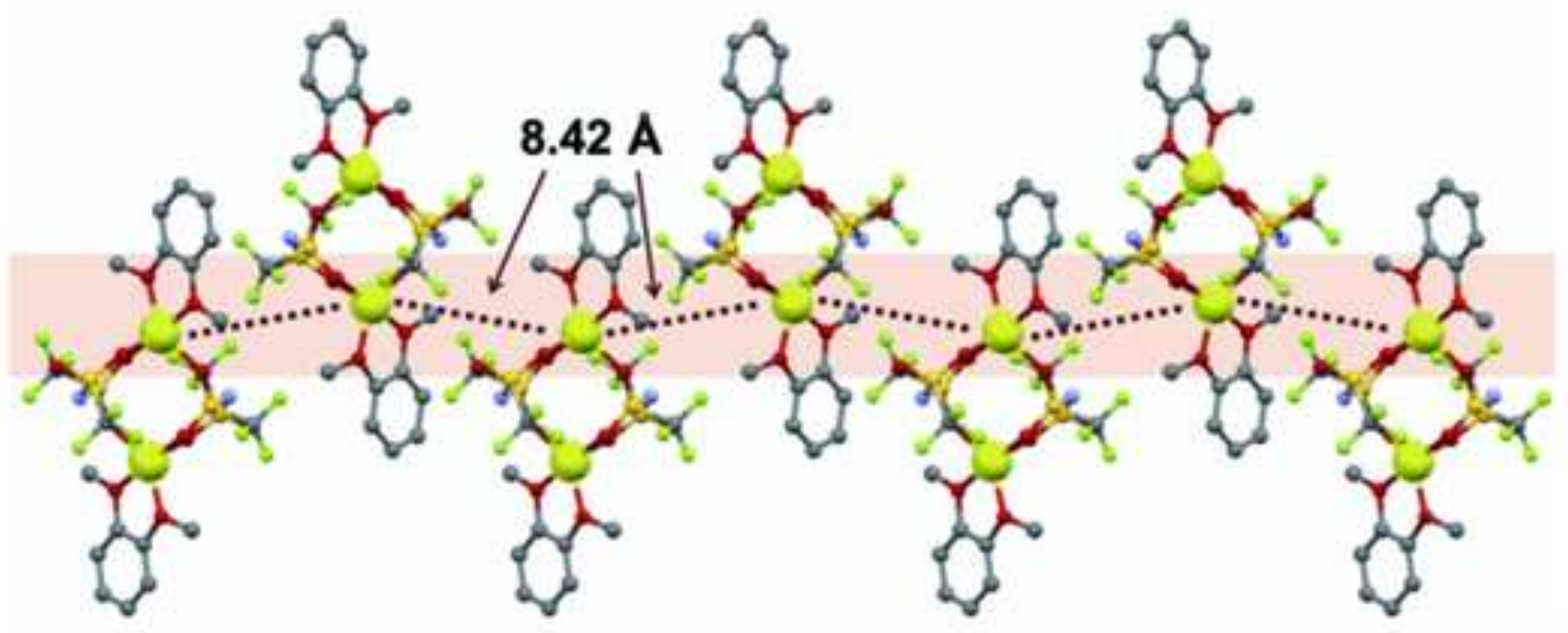



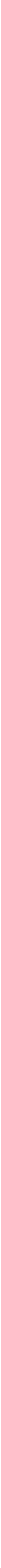


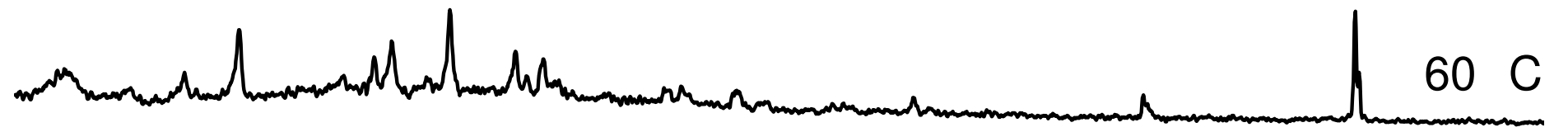

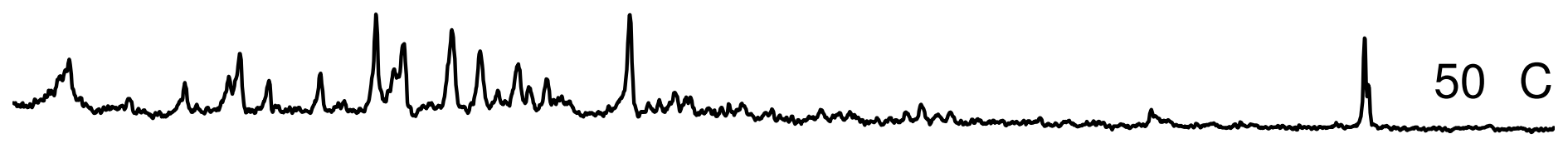

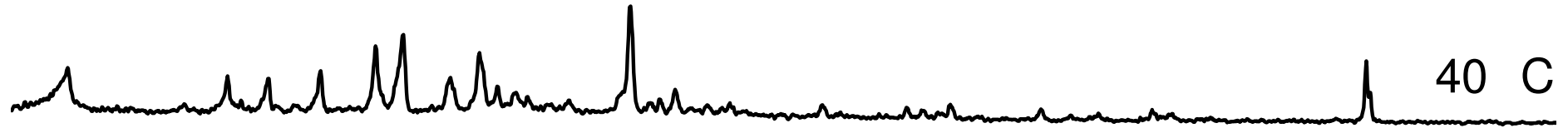

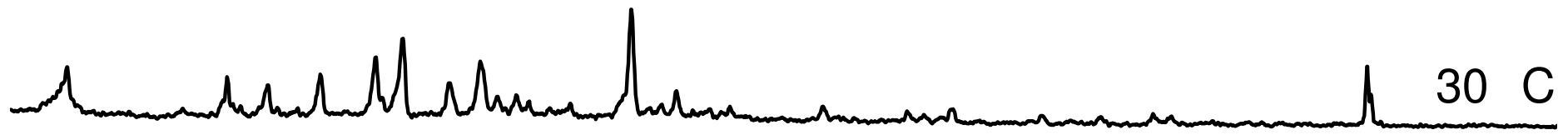

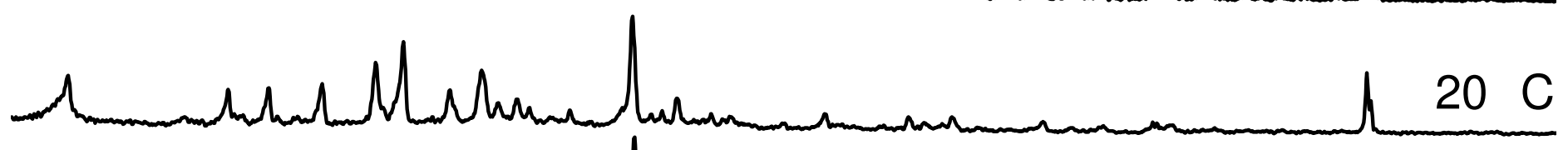

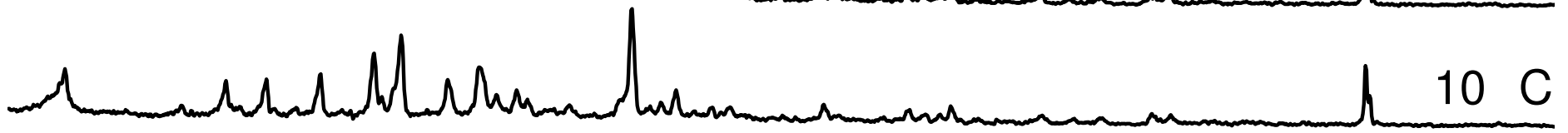

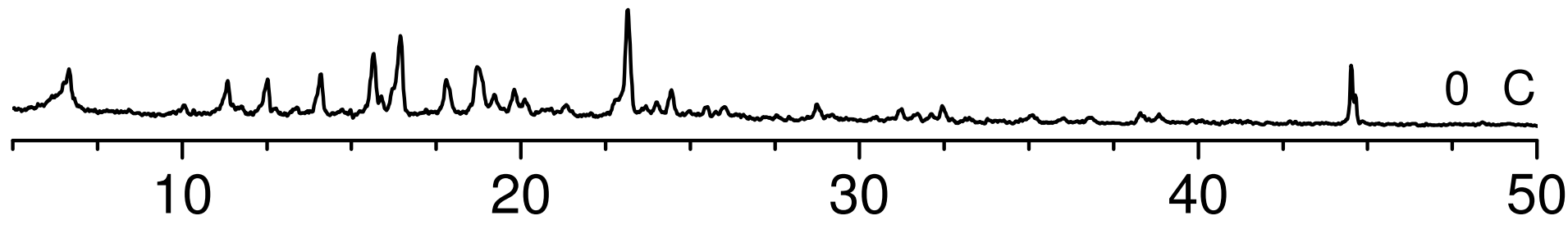
$2 \theta()$ 